\title{
Desafíos de los programas informativos en la neotelevisión
}

\author{
Marcela Farré \\ Universidad Católica San Antonio de Murcia \\ marcefarre@yahoo.es
}

\begin{abstract}
Resumo: Desde a década de 9o, com a conversão das redes televisivas em empresas privadas, comenta-se a respeito de uma guinada em direção à neotelevisão, que implica, sobretudo, o abandono das funções públicas de serviço voltado para o cidadão. Agora, o público é um consumidor e as emissoras são empresas com interesse econômico. Esta mudança radical trouxe consigo uma profunda alteração nos modos de fazer televisão, e o gênero noticioso, apesar de sua identidade informativa, não escapou de tais tendências. Muito se tem questionado acerca dos novos formatos e estilos das notícias; discute-se a ficcionalização e a espetacularização das notícias. Entretanto, já não é possível nem desejável retornar aos esquemas anteriores, supostamente objetivistas. Os questionamentos e as propostas devem situar-se em outro lugar, a partir da própria lógica deste meio e das relações que mantém com uma audiência também nova.
\end{abstract}

Palavras-chave: televisão, notícias, qualidade.

Resumen: Desde la década de los 9o, con la reconversión de las cadenas televisivas en empresas privadas, se habla de un paso hacia la neotelevisión, que implica, sobre todo, el abandono de las funciones públicas de servicio al ciudadano. Ahora, el público es un consumidor y las emisoras son empresas con interés económico. Este cambio radical trajo consigo una profunda alteración de los modos de hacer televisión, y el género noticioso, a pesar de su identidad informativa, no escapó a esas tendencias. Mucho se ha cuestionado sobre los nuevos formatos y estilos de las noticias; se habla de ficción y de espectacularización de las noticias. Sin embargo, ya no es posible ni deseable volver a los esquemas anteriores, pretendidamente objetivistas. Los cuestionamientos y las propuestas deben situarse en otro lugar, a partir de la lógica misma de este medio y de las relaciones que hoy mantiene con una audiencia, también nueva.

Palabras clave: televisión, noticias, calidad.

1 Doctora en Comunicación. Universidad Católica San Antonio de Murcia (España). Autora de El noticiero como mundo posible. Estrategias ficcionales en la información televisiva. (Buenos Aires: Universidad Austral-La Crujía, 2004). 


\begin{abstract}
From the decade of the 90, with the reconversion of the television chains into deprived companies, it is spoken of "neotelevision", which implies, mainly, the abandonment of the public functions of service towards the citizen. From then, audience is considered as a consumer, since the transmitters are companies with economic interests. This radical change brought with himself a deep alteration of the ways to make television, and news, in spite of its informative identity, did not escape to those tendencies. Critics are centered on the spectacularization and fictionalization of news. Nevertheless, is no longer possible nor desirable to return to the previous schemes. Proposals and questions should arise from the characteristics of the television media itself and its relationship with a new audience too.
\end{abstract}

Key words: television, news, quality.

\title{
Neotelevisión y "neonoticiario"
}

Con la penetración de las leyes del mercado en la lógica de la programación, ha cambiado el modo de concebir el medio televisivo. De aquella "paleotelevisión" (Casetti y Odin, 1990), institución al servicio y formación del espectador, hoy sólo se aprecian algunos objetivos, generalmente alrededor de los cometidos de la televisión pública del Estado -cuyo cumplimiento es también discutido (CICOM, 2006)-. Está claro que la "neotelevisión" define un cambio de discurso del medio hacia una lógica de captación del espectador, cambio que se observa definitivamente en la década de los 90, con la progresiva privatización de las diferentes cadenas y a partir del modelo de las networks o cadenas estadounidenses (Cortés, 1999).

Lo propio de la neotelevisión es la búsqueda de la audiencia, algo que se propicia por medio de distintas estrategias de interacción; con la múltiple oferta de contenidos, el televidente es ahora más libre y activo, y por lo mismo, inestable y huidizo. Por eso, la programación se planifica a partir de él, sus horarios y rutinas, sus gustos y, sobre todo, los resortes psicológicos que pueden atraer su interés. Las televisiones privadas ahora lo necesitan, viven de él, y lo buscan de diferentes maneras. 
De esta manera, el nuevo discurso televisivo asume características propias, que devienen de esta relación vital con el espectador/consumidor y que se traspasan también al programa informativo, convertido en "neonoticiario":

- Se promueve la participación de la audiencia, incluso dentro del programa. El talk show es un prototipo de este rasgo neotelevisivo, pues en él los testimonios anónimos y privados se convierten en referencias públicas. Así, la televisión ya no es lugar donde se transmite un saber o un contenido, sino un lugar de encuentro donde todas las opiniones tienen valor. En el neonoticiario también se suscita la participación del espectador de diversos modos: llamadas telefónicas inician la investigación periodística, los testimonios anónimos son la fuente principal de muchas noticias, en el programa los conductores le dirigen actos de habla al espectador y lo implican en el proceso informativo cuando, por ejemplo, los analistas y expertos transmiten un saber al conductor quien se entera -o simula hacerlo- a la vez que el televidente. De esa manera, dos rasgos neotelevisivos asoman: por un lado, el conductor es alguien cercano al espectador, que no lo sabe todo, y, por otro lado, esa condición de sujetos próximos promueve un pacto de lectura más activo, porque el conductor permite que el televidente se identifique con él y así lo lleva consigo hacia la adquisición de la información en el sentido propuesto por el programa.

- En el mismo sentido, se busca la proximidad con la audiencia en todos los aspectos (Farré, 2004). Proximidad en los temas, que pasan al dominio de lo privado e íntimo, incluso en el noticiario; proximidad en los espacios: se informa desde la calle, los lugares cotidianos, el ciudadano común que representa la voz del pueblo, el barrio es la noticia; proximidad, en fin, en el discurso, por la disolución de las fronteras entre géneros. Es este un rasgo característico de la neotelevisión, casi uno que la define.

- La hibridación de los géneros y formatos. Los anteriores principios de "educación, información y entretenimiento" que 
marcaban la división en géneros ya no son válidos. Tampoco la separación temática de los tipos de programas. La neotelevisión reconoce dos grandes macrogéneros, ficción e información, que incluso no se presentan siempre separados, pues las modalidades de uno tiñen las del otro (Ellis, 1992). Es así como se habla de la ficcionalización de las noticias, toda vez que los usos propios de la ficción audiovisual imperan para narrar la información (Farré, 2004). El resultado es un formato híbrido, atractivo y, en ocasiones, espectacularizante. $\mathrm{Y}$ algunas otras, engañoso.

\section{Géneros, formatos y convenciones: definiciones del nuevo programa informativo}

No hace mucho, el 13 de diciembre de 2006, el informativo de la televisión pública de Valonia, Bélgica, anunciaba la acción separatista de Flandes, que autoproclamaba su independencia. Tras la alarma, se supo que el reportaje de la RTBF era una simulación ${ }^{2}$, y que la intención de la cadena era abrir el debate sobre los problemas de diferencias que separan a las comunidades belgas.

En otra oportunidad, por último, una nota de un informativo de la CBS trataba de explicar cómo había sido el impacto, el 11 de septiembre de 2001, de los aviones que se estrellaron contra las Torres Gemelas. El programa lo hacía con dibujos y reconstrucciones digitales. No había aviones reales ni veíamos las torres verdaderas: sabíamos que eran representaciones simbólicas que estaban en el lugar de la realidad, y eran verdad.

\footnotetext{
${ }^{2}$ El término simulación es usado en su acepción más usual, un encubrimiento o engaño. De todas maneras, representa también el concepto que se quiere presentar en esta comunicación, y que se desarrolla más abajo. En ese caso, se verá, hay que precisar que se trata de un tipo de simulación particular, engañosa, que es la "simulación significada" (Bettetini, 1989).
} 
Reportaje de la RTBF, el 13 de diciembre de 2006.

Los dos programas hacían uso informativo de convenciones ajenas al noticiario, y en todos los casos eran estrategias propias del discurso ficcional: la reconstrucción en el caso de la CBS y la simulación de la RTBF. Aun así, los dos programas siguen siendo reconocidos como informativos. Pero, ¿aun así mantienen su estatus frente al espectador y la sociedad? Evidentemente, si algo enseñan estos ejemplos a la audiencia es que en la neotelevisión muchas cosas son posibles y no todas responden a los principios de calidad informativa que se les ha de exigir.

El principal problema de estos usos ficcionales no radica en la hibridación de los formatos. La espectacularidad televisiva es algo inherente al medio y para las generaciones alfabetizadas dentro del mundo audiovisual no constituye un rasgo ajeno ni extraño (Bechelloni, 1989). A la vez, la ficción y sus modos indirectos de referir la realidad es capaz de penetrar en ella con más profundidad y hacerla más comprensible en muchos casos. La ficción contribuye, por un lado, al reconocimiento de un problema o asunto como algo cercano, porque al narrarlo permite una mayor identificación con él y sus protagonistas; y por otro lado, la ficción permite al destinatario tomar una distancia necesaria para asumir una posición personal frente al asunto. Así, el doble proceso de entrañamiento y extrañamiento propio de la ficción (Pavel, 1995) permite asumir la realidad más allá de los datos expuestos. Estrategia interesante si se trata de ayudar al destinatario a comprender mejor la realidad, como demuestran numerosos documentales que, para informar, echan mano de recursos propios del cine.

El problema aparece cuando las estrategias propias de la ficción no son empleadas dentro de la lógica informativa y del pacto de lectura establecido 
tácitamente con el destinatario, sino que son recursos para llamar la atención y provocar, con lo que se genera una sospecha sobre el mismo género noticioso. Como explica Umberto Eco (1981), en la relación mediática preexiste una "dicotomía fundamental" entre ficción e información, que el autor asienta en los modos de comprender y de sancionar que tiene la audiencia.

Sin embargo, en la televisión que conocemos a partir de los años 90, y cuyas tendencias continúan intensificándose hoy, un rasgo fundamental es la ruptura de esas dicotomías claras. Predomina la hibridación y la transgresión, y con ello, la necesidad de repensar el concepto mismo de género. Como dice Lucrecia Escudero (1997), el género es a la vez un principio de coherencia textual y una forma de clasificación; pero en el caso de los medios necesita una precisión, pues allí "el género pondrá en relación no sólo un texto con una serie sino un público con un sistema de producción, contribuyendo a construir la competencia de lectura e interpretación de los consumidores" (Escudero, 1997:76). De esta manera, se advierte que en el discurso televisivo, lo que es posible y reconocible dentro de un género es algo que se va redefiniendo en el proceso, siempre guiado por el pacto de lectura.

Las transgresiones a la norma del género no siempre implican un valor o una superación respecto de los cánones anteriores, sino que por el contrario, pueden suponer en demasiados casos la ruptura de los pactos de lectura con su audiencia, a la que se le pide, sin embargo, creer. Esto resulta particularmente grave en el noticiario, tipo de programa que ha representado siempre un lugar privilegiado en la parrilla de las distintas cadenas por ser el que cifra, de alguna manera, su imagen ante la sociedad (Farré, 2004).

El informativo tiene una función institucional reconocida, de servir e informar, que además el medio afirma explícitamente sobre sí, generando una expectativa acorde. De ese modo, el público espera que el noticiario "cumpla su deber", dice Eco (1981), y que lo haga del siguiente modo: a) diciendo la verdad; b) haciéndolo según criterios de relevancia y proporción y c) separando la información del comentario. En consecuencia, verdad y adecuación es lo que el espectador cree 
que ha de encontrar, fiel por su parte al contrato de lectura que este tipo de programa le ha propuesto de modos que enfatizan la credibilidad. ${ }^{3}$

\section{Información y ficcionalización de la realidad}

La relación entre ficción e información, así como la contaminación de ambos tipos de convenciones, debe analizarse más allá de los usos que definen a una y otra modalidad; como se dijo, hay que pensar también en lo que es aceptable o no a partir de los procesos de consumo textual.

Esto es fundamental en un tipo de programa tan definido institucionalmente como el informativo, en el que la representación de la verdad debe seguir un principio de realismo acorde con el género, con su función, con las expectativas que genera en los espectadores y con las reales responsabilidades sociales que emergen de todo lo anterior.

Por todo ello, definir la ficción es el punto de partida para fundamentar las críticas al hibridismo del noticiario. Pavel (1995) explica que lo que se llama "ficción" dentro de una cultura no está determinado por un único parámetro, con lo que tampoco podrá comprenderse sólo en términos de oposición con lo "real". Para el autor, debe distinguirse entre: a) las preguntas metafísicas sobre los seres de ficción, y su verdad; b) las preguntas sobre la demarcación estilística que permite establecer distinciones estructurales de género entre ficción y no-ficción; y c) las preguntas institucionales relacionadas con el papel de la ficción dentro de una cultura. Se refiere a los aspectos pragmáticos de lo que se considera ficción (y, en consecuencia, información) en un segmento determinado.

Este criterio múltiple nos permite enfrentarnos con herramientas útiles al problema de la "ficcionalización", definida como el empleo de estrategias propias de las convenciones reconocidas para la ficción, en programas no ficcionales. La ficcionalización consistirá en el empleo de unos usos ajenos al género, pero que

\footnotetext{
3 La verosimilitud está construida estratégicamente para cada género. En el caso del informativo, diversos elementos semióticos están allí para definir la verdad, la inmediatez y la urgencia con las que se torna más creíble. Los relojes y mapas, las mesas de redacción detrás de ventanas transparentes a espaldas de los conductores, sus interpelaciones directas, el "lugar de los hechos", los testigos, etc., son todas maneras de enfatizar la "naturaleza factual de los hechos" (van Dijk, 1983).
} 
pueden ser significativos para lograr mejor sus fines, siempre y cuando no impliquen fenómenos de transgresión respecto del pacto.

Por ejemplo, desde a), el aspecto metafísico de la ficción, podemos afirmar que el programa informativo de la CBS incluye seres de ficción como verdaderos, sin serlo. La inclusión tiene valor de "recurso estilístico" (ficción en el sentido de b) con fin informativo, pues los seres que se muestran no representan ningún otro ser identificable en el mundo de referencia del espectador. Sin embargo, no existe inconveniente en interpretar esos gráficos como representaciones reales -de lo real$\mathrm{y}$ por esto funcionan como informativos, no ficcionales, evaluados desde c).

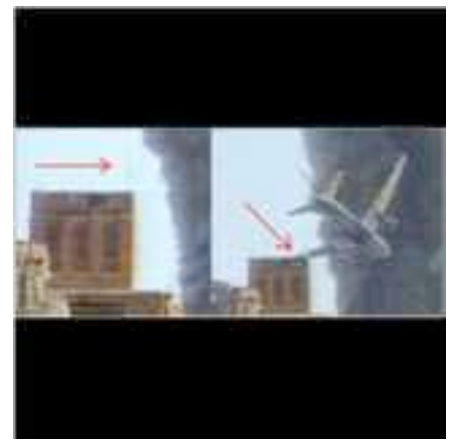

Imágenes de aviones cayendo a pique. (Reconstrucción.) De la galería de fotos online de CNN. (No corresponde al programa que se refiere en el análisis.)

El caso de Bélgica, por su parte, analizado desde esta triple óptica sobre la ficción, lleva a conclusiones interesantes. En el reportaje de RTBF sobre la independencia de Flandes, los seres mostrados (calles, palacios, personajes políticos) son, desde el punto de vista metafísico a) reales. Desde el punto de vista estilístico, b), no puede verse allí ningún elemento que sea reconocido formalmente como propio de la ficción audiovisual. Y teniendo en cuenta la función social e institucional del programa (c), claramente la cadena RTBF de Valonia ha transgredido el principio de información. En este caso, se produce el engaño sin ninguna advertencia pues el texto no prevé que el espectador descodifique este recurso como un uso ficcionalizante con objetivo informativo. Al contrario, la nota fue trabajada para generar el verosímil de género y poder, así, producir el efecto de alarma deseado. ${ }^{4}$

\footnotetext{
4 Los periodistas y el director de la cadena admitieron haber pasado mucho tiempo preparando este escenario y sus efectos. Precisamente, todo estaba construido para que no se desvelara la ficcionalidad de los elementos. Falsas tomas en directo (pero a sitios realmente
} 
Numerosos autores se han dedicado con esfuerzo a distinguir los usos poéticos correspondientes al campo de la ficción y, en su mayoría, se han centrado en rasgos formales de los textos o en su finalidad5. Así, Ducrot \& Todorov (1976) describen que la ficción es de "existencia discursiva", sin referente real, mientras que la no ficción o realidad tiene existencia empírica. Mientras, el discurso periodístico se ha definido por oposición a aquel como reflejo de la realidad y contrario a la "alteración" que se practica en el ficcional (García-Avilés, 1996) ${ }^{6}$.

Cuando se pretende hacer demarcaciones entre ficción y realidad, es fácil caer en dicotomías. No obstante, no se pretende aquí negar la entidad de cada uno de estos dos campos socialmente reconocibles y funcionales. No tendría sentido hablar de ficcionalización si no presumiéramos los dos términos implicados en la palabra, ficción y realidad. El problema radica en pretender asociar una y otra con las nociones de falsedad y verdad, respectivamente. Por el contrario, la ficción es un modo de conocer el mundo en su complejidad y se construye cuando la realidad se disimula en narración y ésta, a su vez, es capaz de simular realidad. Por eso, el de la "ficcionalización" es un campo intermedio que se construye con elementos estructurales propios de la ficción pero con finalidad informativa. El mundo que se construye en él remite a un yo-origen real, identificable, y forman parte de lo que François Jost denomina "el campo de la simulación" (Jost, 1996), que incluye, entre otras, las siguientes estrategias7:

existentes en el presente de la emisión), falsas declaraciones de políticos reales (que se prestaron a actuar) y palabras falsas, por último, en boca del periodista cuyo rostro era también reconocido. En fin, un conjunto de elementos convencionalmente utilizados para hacer creer la verdad de las noticias fueron subvertidos, poniendo al descubierto al menos tres cosas: una, que la ficción no es algo que se dirima en el terreno textual (de los recursos estructurales); otra, constatar el poder de los medios informativos sobre la sociedad y confirmar su función institucional; pro último, y en relación con la segunda, la responsabilidad (o irresponsabilidad) que les cabe a los medios informativos.

5 Las demarcaciones han sido señaladas en disciplinas diversas como la teoría literaria (Ducrot \& Todorov, 1976), en la caracterización del discurso histórico (Ricoeur, 1984), en la cinematografía (Brunetta, 1987), en géneros informativos como el documental (Maqua, 1992) o el periodístico (García-Avilés, 1996; Chillón, 1993).

${ }^{6}$ Un extenso recorrido por los términos de oposición de diversos autores, desde distintos campos discursivos, pueden encontrarse en Farré, 2004 (capítulo 5).

7 Los mecanismos o estrategias que definen el campo de la simulación son expuestos por Jost (1996). Los ejemplos estos, y otros de más estrategias reconocibles, pueden verse en Farré (2004: 195-198). 
- Aludir a lo posible (verosímil) o a un pasado de referencia común con el espectador (lo conocido intertextual).

- Relacionar la representación con lo representado (no real), como más pertinente que su variante empírica. Es el caso de las imágenes de archivo.

- Realizar reportajes en los que la voz narradora asume una supuesta autoría y hace olvidar los efectos de edición y montaje.

- Reconstruir la temporalidad de las noticias, trayéndolas al presente del espectador por obra de la voz narradora del conductor, que sí es simultáneo al tiempo del televidente y ayuda a borrar las distancias. (Es lo propio del discurso informativo, cuya especificidad radica en borrar las huellas de esa ficción narrativa que es, necesaria selección y ordenación del mundo con una visión particular.)

- Mezclar entidades reales con otras ficticias, por ejemplo en la reunión en la pantalla de imágenes originariamente distantes; o de citas dispersas, provocando un efecto de conversación simbólica (por ejemplo, las noticias a partir de entrevistas a una persona o más, a las que se "hace dialogar" pretendidamente). Es, también, el caso del relato o narración, que reúne datos bajo una isotopía dominante (el ejemplo típico de las noticias de sucesos policiales, cuyo desenlace se desconoce pero que el relato periodístico insiste en explicar, con lo cual los datos aparecen vinculados a posibles causas y protagonistas).

En definitiva, en el análisis hay que ir más allá de los rasgos estructurales del texto. Cuando el noticiario apela a recursos estilísticos con la intención de significar, por medio de ellos, una verdad, estamos ante un tipo de ficcionalización que puede asumirse como adecuada al género, dentro de lo específico de la neotelevisión. En estos casos, el texto no se propone llevar a cabo una creación metafísica de entes de ficción sino un intento explicativo por la vía discursiva. Es lo que Bettetini (1989) denomina "simulación significante". En cambio, cuando el recurso se convierte en signo que busca atraer por sí mismo, enmascara el valor de verdad y precisión de lo 
verdadero: es el caso del empleo de elementos ficcionales inadecuados para los fines informativos. En ellos, la simulación puede acarrear situaciones conflictivas como:

- Las distorsiones respecto de su finalidad, en las que la intención del texto se malinterpreta (caso de la televisión de Valonia) y la función institucional del medio queda cuestionada.

- Las descodificaciones aberrantes (Eco), cuando un uso ambiguo no deja claro el carácter ficcional de la simulación, y el espectador toma como verídico algo que no lo es.

- Rechazo e inaceptación del pacto, cuando la simulación se percibe como inadecuada. El programa informativo es entonces objeto de crítica, acusado de hacer "simulacro" y "espectacularización" de la realidad. Una musicalización que carga de pasiones emotivas un texto o un montaje que fuerza la unión de elementos dispares dejan al descubierto unos propósitos bien distintos de los que se espera de un informativo, como veíamos antes al hablar de sus funciones.

\section{Hacia unos informativos de calidad}

El informativo de la televisión de los últimos años se va alejando de las determinaciones convencionales del género. Si antes la verosimilitud se construía con la objetividad de una mirada seria a cámara y mapas detrás del conductor, ahora esto es síntoma de construcción, artificio y hasta simulación (del significado). Hoy los rasgos ficcionales con los que se representan las noticias son, en algunos casos, los que ayudan a interpretarla mejor. Reconstrucciones, animaciones, narraciones, etc. pueden ser capaces de explicar con mayor aptitud un conflicto $u$ otro tipo de información.

Frente a las convenciones del paleonoticiario, el neonoticiario de hoy es un programa con sus propias convenciones, entre las que se encuentra la ficcionalización. Los conductores abren, saludan y se saludan; son cómplices entre sí y con el espectador. Los reportajes incluyen formatos variados (entrevistas, recreaciones, relatos de suspense). Aparecen usos creadores en las imágenes, en el sonido y en el lenguaje, cada vez más simbólico (con significados ambiguos, metafóricos o con remisiones intertextuales). Los temas noticiosos son informados en 
entregas, dentro de la misma emisión, para generar expectativa. Se exhibe el entorno del plató, con sus decorados y las mesas de los que trabajan "detrás de la cocina" (pero ahora son mostrados) y se incluyen temas que antes eran ajenos a un programa periodístico. Son estos algunos aspectos de lo neotelevisivo, no siempre adecuados a la función periodística. Si el objetivo que persiguen es entretener y conseguir la audiencia, entonces los cambios pierden su sentido y allí es cuando emergen las críticas por la falta de calidad de la neotelevisión en general, y de la pérdida de calidad informativa en particular, para aludir al noticiario.

El noticiario espectaculariza -y pierde calidad- cuando, explotando el carácter de la imagen significante, busca despertar las pasiones en el espectador pero sin ánimo de llegar a la verdad. Al contrario, en estos casos el signo se construye para disimularla, distorsionarla, ocultarla ${ }^{8}$. La música en un reportaje puede estar sólo para cargar de fuerza emotiva una noticia y conseguir la adhesión a la pantalla; un montaje puede resultar irresistible, por ejemplo cuando sigue la estética de un videoclip. Pero en ambos casos, el informativo estaría confundiendo los aspectos sustanciales con los accidentales (Bettetini, 1989:94-95). En estos casos, la ficcionalización pasa a ser prerrogativa de un engaño en el pacto de lectura de este tipo de programa.

Entre los parámetros que determinan la calidad de un programa informativo, sobresale la capacidad para representar la realidad, que se mide por la confrontación del contenido del programa con la complejidad de los hechos que informa y su reconocimiento en el mundo de referencia (Rosengren, 1991). En este sentido, la adecuación y la verosimilitud son dos variables fundamentales para valorar la calidad de la información. La primera, la adecuación, describe el grado de propiedad de lo mostrado respecto de la realidad de su referente; la segunda variable, la verosimilitud, en cambio, predica sobre las modalidades discursivas aceptables y reconocidas como posibles dentro del género. Por eso, la ficcionalización tiene unos límites impuestos por el propio género y el pacto de lectura de los televidentes. Sin embargo, como se aprecia en un estudio de la calidad de los informativos de Argentina -del año 2005-, casi un 60\% de las noticias medidas emplean en alguna

\footnotetext{
8 Sobre este aspecto particular, puede leerse el artículo de Fernández Pedemonte (1999), centrado en el análisis de las noticias de sucesos.
} 
medida elementos ficcionales, y lo cierto es que los componentes emotivos y festivos que los caracterizan en su mayoría, buscan ante todo impacto y atracción sensorial. Faltan argumentos que expliquen o situaciones que promuevan una mayor comprensión de lo que ocurre (Fabbro, Farré et al, 2006:77).

"Enfatizar la lógica comercial de este tipo de programas podría poner en peligro la integridad de la comunicación cívica”, advierte Blumler (1992), porque el objetivo de captar la atención deja atrás la necesaria información que, no obstante, promete el programa desde su identidad discursiva misma. Se llega así a considerar la dimensión ética de la simulación, centrada en la responsabilidad de los informadores respecto, no ya sólo del televidente, sino de la sociedad democrática. Los esquemas narrativos de las noticias que vemos muestran que los periodistas caen en rutinas demasiado mecanizadas y repetitivas, a partir de ciertos modelos funcionales para entender algunos acontecimientos. Por ejemplo, la explicación de una protesta, la cobertura informativa de la inmigración, las relaciones entre dos partidos políticos... todos aparecen desde el encuadre de la "oposición”, que resalta los argumentos polémicos, más espectaculares, pasionales ${ }^{9}$. En esos esquemas interpretativos que se reiteran, se afirma siempre el mismo tipo de relación entre los sujetos sociales, sin mucho lugar para un cambio posible. Precisamente, la capacidad para representar la diversidad es una cualidad fundamental de la información televisiva de calidad.

De aquí que con frecuencia, y en las más de las veces con razón, las críticas coinciden en señalar que la televisión presenta un mundo simplificado y no permite transformar situaciones injustas, dado que la espectacularización empaña las intenciones informativas con en entretenimiento puramente catártico, que distrae.

\section{Conclusión}

Con la neotelevisión, el formato televisivo ha cambiado y también es distinta la relación del espectador con el medio; es cierto que, en general, el televidente de hoy está más preparado para descodificar y elegir entre las significaciones que

\footnotetext{
9 Véanse los estudios de cobertura informativa de la inmigración, por ejemplo, en Farré, 2004 (especialmente el capítulo 6) o sobre la representación de grupos políticos y sociales en Álvarez, Farré y Fernández Pedemonte (2003) y los resultados del análisis de la calidad de los informativos en del Bosco, Fabbro, Farré y Piscitelli (2006).
} 
propone el emisor. Pero es necesario insistir en la condición por la que se definen los noticiarios, con las que además insisten en presentarse a su audiencia: "la verdad", "reflejo de la realidad”, “objetividad”, etc. Además, tampoco ha de olvidarse la función institucional que cumplen estos programas, con lo que informar se convierte ya en un deber correlativo al derecho del ciudadano, de ser informado.

Dramatizar, narrar o recrear la realidad no significa necesariamente falsearla. Este peligro existe, pero está más en la falta de profesionalidad, de voluntad de búsqueda de la verdad, y en la falta de creatividad en el uso de las posibilidades de la ficción audiovisual. Los riesgos de caer en la espectacularidad no están tanto en la ficcionalización sino en la pérdida del objetivo informativo que los medios registran al poner en primer término sus propios objetivos empresarios. La falta de ética aparece al querer convencer al espectador que, a pesar de esos objetivos, siguen siendo neutrales, rigurosos y fieles a la misión informativa.

\section{Bibliografía}

ÁLVAREZ, C.; FARRÉ, M. y FERNÁNDEZ PEDEMONTE, D. (2003) Medios de comunicación y protesta social. Buenos Aires: La Crujía-Fundación Honrad Adenauer.

BANDRÉS, E.; GARCÍA-AVILÉS, J. A.; PÉREZ, G. Y PÉREZ, J. (2000) El periodismo en la televisión digital. Buenos Aires: Paidós.

BETTETINI, G. (1989) "Por un establecimiento semiopragmático del conepto de ‘simulación ”. A: AA.VV. Videoculturas de fin de siglo. Madrid: Cátedra.

BRUNETTA, Gian Piero. (1987) Nacimiento del relato cinematográfico. Madrid: Cátedra.

CASETTI, Francesco \& ODIN, Roger. (1990) “De la paléo à la néotelevision: un approche sémiopragmatique". Communications, N. 51, Seuil.

CASETTI, Francesco, DI CHIO, Federico. (1999) Análisis de la televisión. Instrumentos, métodos prácticas de investigación. Barcelona: Paidós.

CHILLÓN, Lluís-Albert. (1993) Literatura i periodismo. Literatura periodística i periodismo literari en el temps de la post ficció. Valencia, Secreatariat de Publicacions de la Universitat d'Alacant.

DEL BOSCO, P.; FABBRO, G.; FARRÉ, M. y PISCITELLI, A. (2006) Calidad televisiva. Estrategias ficcionales en la programación televisiva. Buenos Aires: Universidad Austral-Dunken. 
DUCROT, O. \& TODOROV, T. (1976) Diccionario enciclopédico de las ciencias del lenguaje. México: Siglo XXI.

ECO, U. (1981) "Una dicotomia fondamentale: informazione e finzione". A: WOLF, M. (Comp.) Tra informazione ed evasione. I programmi televisivi di intrattenimento. Torino: VPT-Eri, 1981, pp.2-17.

ELIS, J. (1982) Visible Fictions. London: Routledge.

ESCUDERO, L. (1997) “El secreto como motor narrativo". A: VRÓN, E. \& ESCUDERO, L (Comps.). Telenovela. Ficción popular y mutaciones culturales. Barcelona: Gedisa.

FARRÉ, M. (2004) El noticiero como mundo posible. Estrategias ficcionales en la información televisiva. Buenos Aires: Universidad Austral-La Crujía, Col Inclusiones.

FERNÁNDEZ PEDEMONTE, D. (1999) "La violencia de los signos. Sensacionalismo y carencia de recursos narrativos”. Diálogos de la Comunicación. Revista teórica de la Federación Latinoamericana de Facultades de Comunicación Social. Lima, N. 55, pp. 98-111.

FUNDACIÓN TELEFÓNICA. (2006) Medios de comunicación. Tendencias 'o6. Madrid. Informe.

GARCÍA AVILÉS, J.A. (1996) Periodismo de calidad: Estándares informativos de la CBS, $N B C$ y $A B C$. Pamplona: EUNSA.

GREIMAS, A \&COURTÉS, J. (1979) Semiótica. Diccionario razonado de las ciencias del lenguaje. Madrid: Gredos.

JOST, F. (1996) “El campo de la simulación”. Jornadas de Diseño y discurso audiovisual: Cotidiaeidad de la imagen. Imágenes de lo cotidiano. Buenos Aires: Universidad de Palermo.

MAQUA, J. (1992) El docudrama. Fronteras de la ficción. Madrid: Cátedra.

PAVEL, Th. (1988) (1995). Mundos de ficción. Caracas: Monte Ávila.

RICOEUR, P. Historia y verdad. (1955) (1990). Madrid: Encuentro.

RICOEUR, P. (1984) The Reality of Historical Past. The Aquinas Lecture. Milwakee: Marquette University Press.

RTVA. (2004) Libro de estilo. Canal Sur Televisión y Canal 2 Andalucía. Sevilla: RTVA.

VAN DIJK, T. (1983) La ciencia del texto. Barcelona: Paidós.

VV.AA. (1987) La crisis de la literariedad. Madrid: Taurus.

VV.AA. (1989) Videoculturas de fin de siglo. Madrid: Cátedra. 